EDITORIAL

\title{
Role of drug eluting stents in diabetic patients
}

F Boccara, E Teiger, A Cohen

Heart 2006;92:579-581. doi: 10.1136/hrt.2005.082172

There is a clear need for a large multicentre trial comparing the efficacy of the two available drug eluting stents, sirolimus and paclitaxel, in diabetic patients with multivessel disease

See end of article for authors' affiliations .....................

Correspondence to: Dr Franck Boccara, Cardiology department, Saint-Antoine University and Medical School, Assistance PubliqueHôpitaux de Paris and Université Pierre et Marie Curie (Paris VI), 184, rue du faubourg SaintAntoine, 75571 Paris Cedex 12, France; franck. boccara@sat.aphp.fr

Published Online First 31 January 2006 c oronary artery disease is a major cause of morbidity and mortality in diabetic patients. ${ }^{1}$ Coronary revascularisation, using percutaneous coronary intervention (PCI) and/or coronary artery bypass graft (CABG), has lower prognosis in terms of repeated interventions and mortality in diabetic compared with the nondiabetic population. ${ }^{2}$ In the late 1980s, the BARI trial (1988-1991) demonstrated that diabetic patients with three-vessel disease or two-vessel disease involving the proximal left anterior descending artery had greater survival with CABG compared with PCI (without stenting) $(76.4 \% \vee 55.7 \%, p=0.0011)$ even though at seven years there was no difference in the nondiabetic population. ${ }^{3}$ In a more recent study including patients with multi-vessel disease (ARTS 1$)^{4}$ the rate of event-free survival of the diabetic patients remains better in the CABG group despite a systematic use of stenting in the PCI group. The increased risk of cardiovascular events after $C A B G$ in diabetic patients may be partly due to the higher prevalence of comorbidities including renal failure, congestive heart failure, and peripheral vascular disease. Therefore, the benefits of interventional cardiology in this high risk subgroup of diabetic patients remain to be proven.

\section{BALLOON ANGIOPLASTY VERSUS BARE METAL STENT}

Before the stent era, the rate of coronary restenosis was higher with balloon angioplasty alone in diabetic compared with non-diabetic patients (50-62\% v 25-35\%). ${ }^{5}$ The development of bare metal stents (BMS) and more recently of drug eluting stents (DES) has changed dramatically the prognosis of PCI in this population.

BMS has been associated with a significant improvement in midterm angiographic follow-up in diabetic patients with a similar coronary restenosis rate compared with non-diabetic patients of $25 \%{ }^{6}$ Van Belle et al have shown that the angiographic benefit was correlated with clinical improvement at four years with a reduction in the combined end point (cardiac death and non-fatal myocardial infarction) in the diabetic stenting group compared with the diabetic balloon angioplasty group $(14.8 \% v$ $26.0 \% ; p=0.02$ ) as well as the need for repeated revascularisation $\quad(35.4 \% \quad v \quad 52.1 \%$; $\mathrm{p}=0.001)$.

\section{BMS VERSUS DES}

The superior efficacy of DES compared with BMS to improve outcome and angiographic restenosis is of interest in diabetic patients at particularly high risk of restenosis and cardiovascular events. Only one randomised trial has been designed specifically to address diabetic patients (DIABETES trial). ${ }^{8}$ There was a clear efficacy of the sirolimus stent in reducing both angiographic and clinical parameters of restenosis in both insulin dependent and non-insulin dependent diabetes mellitus. Two meta-analyses, ${ }^{9}{ }^{10}$ including respectively 19 and six studies (8987 and 3669 patients), confirmed the overall clinical and angiographic benefits of DES compared with BMS in the general population.

\section{SIROLIMUS VERSUS PACLITAXEL ELUTING STENT}

In this issue of Heart, Roiron et al, ${ }^{9}$ in an indirect meta-analysis comparing DES and BMS, confirm that the occurrence of major adverse cardiac events (MACE) was highly reduced with DES from $19.9 \%$ to $10.1 \%$ (odds ratio (OR) $0.46,95 \%$ confidence interval (CI) 0.41 to $0.52 ; \mathrm{p}<0.001$ ). The authors, however, point to a significant heterogeneity between subgroups according to the type of DES $(p<0.001)$ : MACE OR was 0.28 (95\% CI 0.25 to 0.35 ) in the sirolimus group and 0.62 (95\% CI 0.53 to 0.73 ) in the paclitaxel group (indirect comparison). The restenosis rate was also reduced with DES (from $31.7 \%$ to $10.5 \%$ ) with a similar heterogeneity between the two devices. In this meta-analysis, a trend toward an increased risk of non-Q wave myocardial infarction (MI) and stent thrombosis was observed with paclitaxel. However, mortality, Q wave MI and stent thrombosis rates were similar. Kastrati et $a{ }^{10}{ }^{10}$ in a recent meta-analysis of head to head trials, reported the same difference in favour of the sirolimus eluting stent, although the risk of death or MI was not significantly different between the two DES.

\section{SIROLIMUS VERSUS PACLITAXEL ELUTING STENT IN DIABETIC PATIENTS}

Also in this issue of Heart, Stettler et $a l^{11}$ report a meta-analysis comparing indirectly the two DES ( six studies with sirolimus and four studies with paclitaxel) with BMS in de novo coronary lesions

Abbreviations: $B M S$, bare metal stents; $C A B G$, coronary artery bypass graft surgery; $\mathrm{Cl}$, confidence interval; DES, drug eluting stents; MACE, major adverse cardiac events; $\mathrm{MI}$, myocardial infarction; OR, odds ratio; $\mathrm{PCl}$, percutaneous coronary intervention 
Table 1 Studies comparing sirolimus to paclitaxel eluting stents in series including a sufficient number of diabetic patients

\begin{tabular}{|c|c|c|c|c|c|c|c|}
\hline $\begin{array}{l}\text { Studies and } \\
\text { follow up }\end{array}$ & $\begin{array}{l}\text { No. diabetic } \\
\text { patients } \\
\text { S/P }\end{array}$ & $\begin{array}{l}\text { Mean RVD Mean LL } \\
(\mathrm{mm}) \\
S \vee P\end{array}$ & $\begin{array}{l}\text { Late loss }(\mathrm{mm}) \\
S \vee P\end{array}$ & $\begin{array}{l}\text { Angiographic in } \\
\text { segment restenosis } \\
S \vee P\end{array}$ & $\begin{array}{l}\text { TVR } \\
S \vee P\end{array}$ & $\begin{array}{l}\text { MACE } \\
S \vee P\end{array}$ & $\begin{array}{l}\text { Results } \\
\mathrm{S} \vee \mathrm{P}\end{array}$ \\
\hline $\begin{array}{l}\text { ISAR-D } \\
9 \text { months }\end{array}$ & $125 / 125$ & $\begin{array}{l}2.7 \vee 2.75 \\
13.8 \vee 12.4\end{array}$ & $\begin{array}{l}\text { In segment } \\
0.43(0.45) v \\
0.67(0.62), p=0.002\end{array}$ & $6.9 \%$ v $16.5 \% p=0.03$ & $\begin{array}{l}\text { TLR } \\
6.4 \% \vee 12 \% \\
p=0.13\end{array}$ & NR & $S>P$ \\
\hline $\begin{array}{l}\text { REALITY*13 } \\
8 \text { months }\end{array}$ & $186 / 192$ & $\begin{array}{l}2.4 \vee 2.4 \\
16.96 \vee 17.31\end{array}$ & $\begin{array}{l}\text { In stent } 0.09 \vee 0.31 \\
p<0.05\end{array}$ & $9.6 \% \vee 11.1 \%, p=N S$ & $\begin{array}{l}1.6 \% \vee 1.2 \% \\
p=N S\end{array}$ & $\begin{array}{l}9.2 \% \text { v } 10.8 \% \\
p=N S\end{array}$ & $S=P$ \\
\hline $\begin{array}{l}\text { SIRTAX*14 } \\
9 \text { months }\end{array}$ & $108 / 93$ & $\begin{array}{l}2.82(0.42) v \\
2.82(0.43) \\
11.8(6.8) v \\
12.4(7.2)\end{array}$ & $\begin{array}{l}\text { In stent } 0.13 \vee 0.25 \\
p<0.05\end{array}$ & $6.6 \% \vee 11.7 \%, p=0.02$ & $\begin{array}{l}6.0 \% \vee 9.2 \% \\
p=0.05\end{array}$ & $\begin{array}{l}6.2 \% \vee 10.8 \% \\
p=0.009\end{array}$ & $S>P$ \\
\hline $\begin{array}{l}\text { Stettler }{ }^{11} \\
\text { Indirect meta- } \\
\text { analysis } \\
6-9 \text { months }\end{array}$ & $652 / 494$ & $\begin{array}{l}2.52 \vee 2.81 \\
13.2 \vee 13.95\end{array}$ & NR & $\begin{array}{l}\text { Ratio of incidence rate } \\
\text { ratios } 1.51, p=0.31\end{array}$ & $\begin{array}{l}\text { TLR ratio of } \\
\text { incidence rate } \\
\text { ratios } 0.81 \text {, } \\
p=0.7\end{array}$ & $\begin{array}{l}\text { Ratio of incidence } \\
\text { rate ratios } 0.6 \text {, } \\
p=0.33\end{array}$ & $S=P$ \\
\hline
\end{tabular}

*Results are given for the entire cohort including diabetic and non-diabetic patients.

$\mathrm{LL}$, lesion length; NR, not reported; P, paclitaxel; RVD, reference vessel diameter; S, sirolimus; TLR, target lesion revascularisation; TVR, target vessel revascularisation.

in patients with or without diabetes mellitus. The authors have convincingly shown that in patients without diabetes, sirolimus DES was superior to paclitaxel with respect to instent and in-segment restenosis, target lesion revascularisation and MACE. However, in diabetic patients, this difference disappeared. Few studies have focused on specific outcome of DES in diabetic patients (table 1). Only one study, the ISARDiabetes study, ${ }^{12}$ enrolled only diabetic patients (250) in two centres in a direct non-inferiority trial comparing the sirolimus and the paclitaxel DES. The primary end point was the in-segment late luminal loss measured by computerassisted quantitative angiography. There was less late loss with sirolimus than paclitaxel DES $(0.43 \mathrm{~mm} v 0.67 \mathrm{~mm})$. However, this study was not sufficiently powered to assess difference in term of ischaemia-driven revascularisation and MACE. In fact, there is no randomised, controlled multicentre trial with a primary clinical end point and adequate power aiming at demonstrating that one DES is superior to another in the diabetic population.

Two other studies assumed superiority of the sirolimus over the paclitaxel DES (REALITY ${ }^{13}$ and SIRTAX ${ }^{14}$ ) and had enrolled a substantial number of diabetic patients, although the subanalysis according to the diabetic status was not the primary end point. REALITY, ${ }^{13}$ a randomised, prospective, multicentre study including 378 diabetic patients among 1353 patients, observed a greater late loss in the paclitaxel group than in the sirolimus group; however, this loss was not associated with a higher rate of target lesion revascularisation (table 1).

SIRTAX, ${ }^{14}$ a randomised single-centre study including 201 diabetics among a total of 1012 patient, stratified analysis of the primary end point (MACE defined as death from cardiac causes, MI, and ischaemia-driven revascularisation of the target lesion). The study revealed that the difference between sirolimus and paclitaxel DES was more pronounced among patients with diabetes (hazard ratio (HR) $0.31,95 \%$ CI 0.12 to 0.78 ) than among patients without diabetes (HR 0.66, 95\% CI 0.40 to 1.09 ), but confidence intervals were wide, and the result of an interaction test was not significant ( $\mathrm{p}$ for interaction $=0.13$ ).

Finally, the meta-analysis of Stettler et al ${ }^{11}$ revealed no difference between sirolimus and paclitaxel eluting DES in diabetic patients in terms of target lesion revascularisation and MACE. It is of interest to note that in this meta-analysis the mean reference vessel diameter for the overall population was lower in the sirolimus studies compared with the paclitaxel studies $(2.52 \mathrm{~mm} v 2.81 \mathrm{~mm})$ with the same mean lesion length (13.2 mm $v 13.95 \mathrm{~mm}$ ). This difference should emphasise the better efficacy of the sirolimus DES because of its impact on restenosis; however, these specific data are missing in diabetic patients.

Why such a discrepancy between these studies? Indeed, they do differ in terms of type of lesion (complex versus simple) and number of lesions (one single lesion versus multi-lesion). They also differ with regard to study designs: head to head comparison study, indirect or head to head meta-analysis, size of samples, single or multicentre investigators, angiographic and/or clinical follow up, duration of follow up, end point criteria, late luminal loss, target lesion revascularisation, ischaemia-driven target vessel revascularisation, and MACE.

\section{IS THERE A PHYSIOLOGICAL REASON FOR A DIFFERENCE BETWEEN THE TWO DES?}

As highlighted by Stettler et al, ${ }^{11}$ the components of the two DES - the underlying stent, the drug delivery polymer, and the antiproliferative agent (sirolimus as an immunosuppressant agent, paclitaxel as an antineoplastic agent)-are different. In a recent editorial, Moliterno ${ }^{15}$ emphasised the differences between the two antiproliferative agents as cell cycle inhibitors with different mechanisms of action and the timing of their polymer-based delivery. Although this difference is of potential interest to prevent restenosis and luminal late loss in diabetic patients in favour of the sirolimus eluting stent, translation into clinical benefit remains to be proven.

There is concern about the unknown rate of acute and late stent thrombosis and the difference between the two DES in diabetic patients as diabetes mellitus is a significant predictor of stent thrombosis (HR 3.71, 95\% CI 1.74 to 7.89 ; $\mathrm{p}=0.001)$ after premature antiplatelet treatment discontinuation, renal failure and bifurcation lesions. ${ }^{16}$

Finally, the impact of treatment for diabetes mellitus (insulin versus oral antidiabetic drugs) on angiographic and clinical end points after PCI with the two DES remains to be evaluated.

In conclusion, there is a clear need for a large multicentre trial comparing the efficacy of the two available DES with a clinical primary end point at an adequate power involving diabetic patients with multivessel disease. As stated recently by Colombo et al, ${ }^{17}$ there is still room for further progress, especially in high-risk lesions in high-risk patients such as diabetics, and to move from the complex lesion to the complex patient. 


\section{Authors' affiliations}

F Boccara, A Cohen, Department of Cardiology, Saint Antoine University Hospital. Assistance Publique-Hôpitaux de Paris and Université Paris VI, Paris, France

E Teiger, Department of Physiopathology, Henri Mondor University Hospital, Assistance Publique-Hôpitaux de Paris and Université Paris XII, Creteil, France

\section{REFERENCES}

1 Haffner SM, Lehto S, Ronnemaa T, et al. Mortality from coronary heart disease in subjects with type 2 diabetes and in nondiabetic subjects with and without prior myocardial infarction. N Engl J Med 1998;339:229-34.

2 Gu K, Cowie CC, Harris MI. Diabetes and decline in heart disease mortality in US adults. JAMA 1999;281:1291-7.

3 Berger PB, Velianou JL, Aslanidou Vlachos H, et al for the BARI Investigators. Survival following coronary angioplasty versus coronary artery bypass surgery in anatomic subsets in which coronary artery bypass surgery improves survival compared with medical therapy. Results from the bypass angioplasty revascularization investigation (BARI). J Am Coll Cardiol 2001;38:1440-9.

4 Legrand V, Serruys PW MD, Unger F, et al on behalf of the Arterial Revascularization Therapy Study (ARTS) Investigators. Three-year outcome after coronary stenting versus bypass surgery for the treatment of multivessel disease. Circulation 2004;109:1114-20.

5 Holmes DR Jr, Vlietstra RE, Smith HC, et al. Restenosis after percutaneous transluminal coronary angioplasty (PTCA): a report from the PTCA Registry of the National Heart, Lung, and Blood Institute. Am J Cardiol 1984;53:77C-81C.

6 Van Belle E, Bauters C, Hubert E, et al. Restenosis rates in diabetic patients: a comparison of coronary stenting and balloon angioplasty in native coronary vessels. Circulation 1997;96:1454-60.
7 Van Belle $E$, Perie $M$, Braune $D$, et al. Effects of coronary stenting on vessel patency and long-term clinical outcome after percutaneous coronary revascularization in diabetic patients. J Am Coll Cardiol 2002;40:410-7.

8 Sabate M, Jimenez-Quevedo P, Angiolillo DJ, et al for the DIABETES Investigators. Randomized comparison of sirolimus-eluting stent versus standard stent for percutaneous coronary revascularization in diabetic patients: the diabetes and sirolimus-eluting stent (DIABETES) trial. Circulation 2005; 1 12:2175-83.

9 Roiron C, Sanchez P, Bouzamondo A, et al. Drug eluting stents: an updated meta-analysis of randomised controlled trials. Heart 2006;92:641-9.

10 Kastrati A, Dibra A, Eberle S, et al. Sirolimus-eluting stents vs paclitaxeleluting stents in patients with coronary artery disease: meta-analysis of randomized trials. JAMA 2005;294:819-25.

11 Stettler C, Allemann S, Egger M, et al. Efficacy of drug eluting stents in patients with and without diabetes mellitus: indirect comparison of controlled trials. Heart 2006;92:650-7.

12 Dibra A, Kastrati A, Mehilli J, et al ISAR-DIABETES Study Investigators. Paclitaxel-eluting or sirolimus-eluting stents to prevent restenosis in diabetic patients. N Engl J Med 2005;353:663-70.

13 Morice M-C, Serruys PW, Colombo A, et al. Eight-month outcome of the REALITY study: a prospective, randomized, multicenter head-to-head comparison of the sirolimus-eluting stent (Cypher) and the paclitaxel-eluting stent (Taxus). Presented at the 2005 Annual Scientific Session of the American College of Cardiology, Orlando, Florida, March 6-9, 2005.

14 Windecker S, Remondino A, Eberli FR, et al. Sirolimus-eluting and paclitaxeleluting stents for coronary revascularization. $N$ Engl J Med 2005;353:653-62.

15 Moliterno DJ. Healing Achilles-sirolimus versus paclitaxel. N Engl J Med 2005;353:724-7

16 lakovou I, Schmidt T, Bonizzoni E, et al. Incidence, predictors, and outcome of thrombosis after successful implantation of drug-eluting stents. JAMA 2005;293:2126-30.

17 Colombo A, Cosgrave J. Paclitaxel-eluting stents in complex lesions. JAMA 2005;294: 1268-70.

\section{IMAGES IN CARDIOLOGY}

Double coarctation and double grafts: role of computed tomographic angiography in diagnosis of a clinic mystery

A 27 year old woman was admitted to our clinic with left upper extremity pain of two months' duration. History of the patient revealed two operations for coarctation of the aorta. The left subclavian artery to descending thoracic aorta and the ascending aorta to descending thoracic aorta grafts were interposed at 2002 and 2003, respectively. Blood pressure was $120 / 80 \mathrm{~mm} \mathrm{Hg}$ from the right brachial artery, 70/40 mm $\mathrm{Hg}$ from the left brachial artery, and 90/60 mm Hg from the left and right popliteal arteries. Auscultation revealed second degree systolic ejection murmur at the left upper sternal border radiating to the interscapular area. To define the underlying cause of the extremity pain computed tomographic (CT) angiography was performed. Three dimensional CT angiography (see panel) identified the proximal (asterisk) and distal (double asterisk) coarctation segments, the two grafts, and the occluded left subclavian artery. Unfortunately, the first graft (arrowhead) was interposed between the left subclavian artery and the descending aorta in between the two coarctation segments which, possibly, made a second operation necessary. The second graft (arrow) was interposed between the ascending aorta (Asc. Ao) and descending thoracic aorta (Desc. Ao). Shunting of blood via the aorta-aortic graft and the recent operation may be the underlying causes of the left subclavian artery occlusion and left upper extremity pain. CT angiography provides suitable images for the diagnosis and localisation of coarctation of the aorta, which may aid in surgical planning.

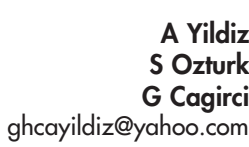

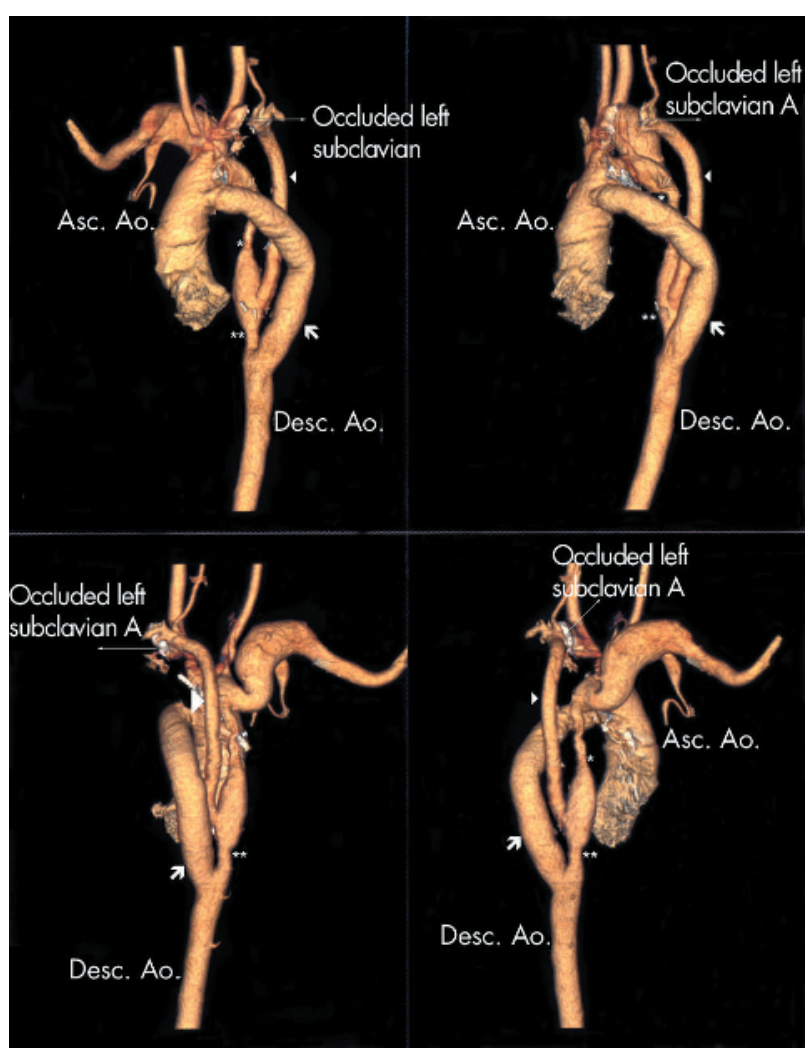

